\title{
Three-year risk of cardiovascular disease among intensive care patients with acute kidney injury: a population-based cohort study
}

Henrik Gammelager ${ }^{1 *}$, Christian Fynbo Christiansen ${ }^{1}$, Martin Berg Johansen ${ }^{1}$, Else Tønnesen², Bente Jespersen ${ }^{3}$ and Henrik Toft Sørensen ${ }^{1}$

\begin{abstract}
Introduction: Acute kidney injury (AKI) is common among intensive care unit (ICU) patients, but follow-up data on subsequent risk of cardiovascular disease remain sparse. We examined the impact of AKI on three-year risk of first-time heart failure, myocardial infarction (MI), and stroke among ICU patients surviving to hospital discharge, and whether this risk is modified by renal recovery before hospital discharge.

Methods: We used population-based medical registries to identify all adult patients admitted to an ICU in Northern Denmark between 2005 and 2010 who survived to hospital discharge and who had no previous or concurrent diagnosis of heart failure, MI, or stroke. AKI was defined according to the creatinine criteria in the Kidney Disease Improving Global Outcomes classification. We computed the three-year cumulative risk of hospitalization with heart failure, MI, and stroke for patients with and without AKI and the hazard ratios (HRs), using a Cox model adjusted for potential confounders.

Results: Among 21,556 ICU patients surviving to hospital discharge, 4,792 (22.2\%) had an AKI episode. Three-year cumulative risk of heart failure was 2.2\% in patients without AKI, 5.0\% for AKI stage 1, and 5.0\% for stages 2 to 3. The corresponding adjusted HRs were 1.33 (95\% confidence interval (CI), 1.06 to 1.66) for patients with AKI stage 1 and 1.45 (95\% Cl, 1.14 to 1.84) for AKI stages 2 to 3, compared to patients without AKI. The three-year cumulative MI risk was 1.0\% for patients without AKI, 1.8\% for patients with AKI stage 1 and $2.3 \%$ for patients with AKI stages 2 to 3. The adjusted HR for MI was 1.04 (95\% Cl, 0.71 to 1.51) for patients with AKl stage 1 and 1.51 (95\% Cl, 1.05 to 2.18) for patients with AKI stages 2 to 3, compared with patients without AKI. We found no association between AKI and stroke. The increased risk of heart failure and Ml persisted in patients with renal recovery before discharge, although it was less pronounced than in patients without renal recovery.
\end{abstract}

Conclusions: ICU patients surviving any stage of AKI are at increased three-year risk of heart failure, but not stroke. Only AKI stages 2 to 3 are associated with increased Ml risk.

\section{Introduction}

Acute kidney injury (AKI), which occurs in $22 \%$ to $67 \%$ of intensive care unit (ICU) patients [1-5], is associated with increased risk of both chronic kidney disease (CKD) and death [1-8].

AKI also may have long-term adverse cardiovascular effects [9]. The potentially increased risk of cardiovascular disease following AKI might be mediated through

\footnotetext{
*Correspondence: hg@clin.au.dk

1 Department of Clinical Epidemiology, Aarhus University Hospital, Olof Palmes Allé 43-45, Aarhus DK-8200, Denmark

Full list of author information is available at the end of the article
}

chronic renal impairment, a well-known risk factor of cardiovascular disease [10]. In addition, animal studies have shown that AKI causes a systematic inflammatory response and activation of the renin-angiotensin system, subsequently promoting apoptosis and interstitial/perivascular fibrosis in the myocardium, and ultimately cardiac dysfunction $[11,12]$.

These findings are supported by a few cohort studies in humans, which reported that patients with AKI as a complication to myocardial infarction (MI), coronary intervention, or heart failure (HF) have an increased risk of subsequent HF and MI [13-18]. AKI during hospitalization also increases the risk of subsequent HF in patients infected 
with human immunodeficiency virus (HIV) [19]. However, it is not known whether AKI has similar implications for incident HF and MI among ICU patients, among whom AKI is common [1-5]. Although it has been suggested that AKI may increase stroke risk [20], the potential association between AKI and long-term stroke risk has received little attention [13].

We therefore conducted a population-based cohort study to examine (1) the impact of AKI on three-year risk of first-time HF, MI, and stroke among ICU patients surviving to hospital discharge, and (2) whether recovery of renal function before hospital discharge modifies subsequent risk of these cardiovascular diseases.

\section{Methods}

\section{Setting}

We conducted this cohort study using population-based medical databases in Northern Denmark with approximately 1.15 million inhabitants.

The Danish health care system provides tax-funded health care to all Danish residents. The study region has 12 ICUs, eight at university hospitals (one cardiothoracic, one mixed cardiothoracic and multidisciplinary, one mixed neurosurgery and multidisciplinary, one neurosurgical, and four multidisciplinary) and four at regional hospitals (all multidisciplinary). The unique civil registration number assigned to all Danish residents allowed us to link Danish medical and administrative databases [21].

\section{Intensive care patients}

We used the Danish National Registry of Patients (DNRP) covering all Danish hospitals to identify all adult residents of Northern Denmark (aged 15 years or older) who had a first-time ICU admission from 1 January 2005 to 31 December 2010 and who survived to hospital discharge. We required one year of residency in the study region to ensure availability of previous test results from the regional laboratory database. The study period was chosen based on availability of data. The DNRP includes data on all nonpsychiatric hospitalizations in Denmark since 1977. Since 1995, the DNRP also has included data from outpatient clinic visits, emergency room visits, and psychiatric units. The DNRP records patients' civil registration number, treating hospital and department, dates of admission and discharge, type of admission (emergency vs. planned), surgical and other major procedures performed, ICU admissions and treatments, and one primary and up to 19 secondary discharge diagnoses assigned by the discharging physician. According to Danish guidelines, the primary diagnosis is the main reason for the hospital admission. Since 1994, discharge diagnoses have been coded using the International Classification of Diseases, $10^{\text {th }}$ revision (ICD-10) [22]. We used the primary ICD-10 diagnosis for the current hospitalization to categorize patients into one of the following eight major disease groups: infectious disease, endocrine disease, cardiovascular disease, respiratory disease, gastrointestinal or liver disease, cancer, trauma or poisoning, and other. In addition, we categorized patients into five groups according to surgical status: no surgery, acute cardiac surgery, acute noncardiac surgery, elective cardiac surgery, and elective noncardiac surgery [6].

\section{Acute kidney injury}

We used the population-based laboratory database that covers the study region to identify occurrences of AKI. The laboratory database contains test results from all inpatient stays, outpatient clinic visits, and visits to general practitioners [23]. We classified AKI according to the serum creatinine criteria in the Kidney Disease Improving Global Outcome (KDIGO) AKI classification (Table 1) [24]. We searched the laboratory database for the highest plasma creatinine (equivalent to serum creatinine [25]) value from ICU admission until hospital discharge to determine the highest level of AKI. All other ICU patients were classified as being 'without AKI'. We defined the baseline creatinine level as the most recent creatinine measurement from an outpatient clinic or general practitioner visit in the period from one year to seven days before the current hospitalization [26]. Plasma creatinine assessments later than seven days before the current hospitalization were not considered, because acute renal impairment may precede the admission. For patients without CKD who lacked a baseline creatinine measurement, we estimated baseline creatinine using the four-variable version of the Modification of Diet in Renal Disease (MDRD) equation based on age, race, and gender, as recommended by the Second International Consensus Conference of the Acute Dialysis Quality Initiative (ADQI) Group [27]. Patients previously treated with chronic dialysis or hemofiltration, those with a

\begin{tabular}{l} 
Table $\mathbf{1}$ KDIGO serum creatinine classification of acute \\
kidney injury [24] \\
\begin{tabular}{ll} 
Stage & Serum creatinine criteria \\
\hline 1 & $1.5-1.9$ times baseline \\
& OR \\
& $\geq 26.55 \mu \mathrm{mol} / /(0.3 \mathrm{mg} / \mathrm{dl})$ increase within 48 hours $^{\mathrm{a}}$ \\
& $2.0-2.9$ times baseline \\
2 & $\geq 3.0$ times baseline \\
3 & OR \\
& Increase in serum creatinine to $\geq 354 \mu \mathrm{mol} / \mathrm{l}(4.0 \mathrm{mg} / \mathrm{dl})^{\mathrm{b}}$ \\
& OR \\
& Initiation of renal replacement therapy
\end{tabular} \\
\hline
\end{tabular}

${ }^{\mathrm{a}}$ We defined 48 hours as two calendar days; ${ }^{\mathrm{b}}$ together with fulfillment of any of the other criteria for acute kidney injury. KDIGO, Kidney Disease Improving Global Outcomes. 
previous kidney transplant, and those lacking information on plasma creatinine levels following ICU admission were excluded from the study.

\section{Heart failure, myocardial infarction, and stroke}

Study outcomes were any hospital admission with a diagnosis of HF, MI, or stroke (ischemic and hemorrhagic cerebral stroke) registered in the DNRP subsequent to the current hospital admission up to three years after hospital discharge. In order to exclude prevalent cases, we omitted all patients with any previous diagnosis of $\mathrm{HF}, \mathrm{MI}$, or stroke up to 10 years prior to or during the admission.

\section{Renal recovery at hospital discharge}

Patients were considered to have achieved renal recovery at hospital discharge if they did not receive any type of dialysis or hemofiltration treatment up to seven days before hospital discharge and their last plasma creatinine measurement before discharge was less than 50\% above their baseline level, that is, they no longer fulfilled the criteria for AKI [28].

\section{Covariates}

We obtained data on covariates potentially associated with both AKI and the study outcomes from the DNRP [22], the laboratory database [23], and the Aarhus University Prescription Database covering all community pharmacies in the study region [29].

Data on comorbidities were primarily obtained from the DNRP, including inpatient or outpatient clinic diagnoses up to 10 years before the current hospitalization. Because many patients with diabetes are treated outside hospitals, we also defined patients as having diabetes if they had a hemoglobin A1c level at or above 6.5\% [30] in the laboratory database up to one year before the current admission or had any prescription for an antidiabetic drug (insulin or oral antidiabetic agent) in the Aarhus University Prescription Database up to five years before the current admission. Diabetes patients who were identified solely by a prescription of metformin and who had coexisting polycystic ovary syndrome were classified as not having diabetes. The Aarhus University Prescription Database contains information on all filled drug prescriptions in the study region. Variables included in this database are patients' civil registration number, type of drug according to the Anatomic Therapeutic Chemical Classification System (ATC), dosage, and prescription date [29]. Information on CKD was obtained from the laboratory database, defined as estimated glomerular filtration rate (eGFR) below $60 \mathrm{ml} / \mathrm{min}$ per $1.73 \mathrm{~m}^{2}$ using the four-variable MDRD equation (stage 3 or higher CKD according to National Kidney Foundation guidelines) [24]. We used the most recent plasma creatinine measurement from an outpatient clinic or general practitioner visit within one year to seven days before the current hospitalization to compute the eGFR [26]. Patients lacking a plasma creatinine measurement were considered as not having CKD. We also retrieved information on preadmission drug use, defined as a prescription filled from 90 days before the current hospitalization until hospital admission [31]. Information was obtained for all drugs listed in Table 2.

All relevant codes used to retrieve data from the DNRP, the laboratory database, and the Aarhus University Prescription Database are provided in Additional file 1.

\section{Statistical analyses}

For each outcome, we followed patients from date of hospital discharge for up to three years or until first-time hospital admission with a study outcome of death or the end of follow-up on 31 December 2011, whichever came first.

We used the cumulative incidence method to plot and compute the crude three-year cumulative risk of admission with $\mathrm{HF}, \mathrm{MI}$, or stroke for patients with AKI stage 1, AKI stages 2 to 3 , and those without AKI, taking death into account as a competing risk [32]. Using hazard ratios (HRs) computed with Cox regression models, we compared the risk of each outcome for patients with AKI stage 1 and AKI stages 2 to 3 with that of patients without AKI [33]. In multivariate analyses we adjusted for the following potential confounders: age, gender, other heart disease, other cerebrovascular disease, hypertension, peripheral vascular disease, diabetes, CKD, cancer, surgical status at ICU admission, primary diagnosis during current hospitalization, and preadmission use of any drug listed in Table 2. To examine the influence of renal recovery on subsequent cardiovascular disease risk, we stratified the analysis by renal recovery status at hospital discharge. All estimates were reported with 95\% confidence intervals $(\mathrm{CI})$.

We conducted a sensitivity analysis to examine the potential influence of excluding patients without a plasma creatinine measurement for each outcome of interest. We imputed AKI levels for patient without a creatinine measurement using multiple imputation [34-36]. HRs for each outcome was calculated as the average HR of the five datasets, corrected for between- and withinimputation variation [34-36]. The imputation models included all variables in Table 2 , the outcome of interest, and the Nelson Aalen estimator of the cumulative baseline hazard evaluated at the observed survival time [37].

The assumption of proportional hazards for all Cox regression models was assessed graphically using log (-log(survival probability))-plots and found valid. Analyses were performed using the statistical software package Stata, version 11.1 (StataCorp LP, College Station, TX, USA).

All data were obtained from Danish registries, which are generally available to researchers without ethics approval or informed consent $[38,39]$. The study was approved by 
Table 2 Patient characteristics by AKI status among ICU patients surviving to hospital discharge, Northern Denmark, 2005 to 2010

\begin{tabular}{|c|c|c|c|}
\hline & $\begin{array}{l}\text { Without AKI } \\
n=16,764\end{array}$ & $\begin{array}{l}\text { AKI stage } 1 \\
n=2,666\end{array}$ & $\begin{array}{l}\text { AKI stages } 2-3 \\
n=2,126\end{array}$ \\
\hline \multicolumn{4}{|l|}{ Age } \\
\hline Age, median (IQR) & $57(39-69)$ & $68(58-77)$ & $67(56-75)$ \\
\hline \multicolumn{4}{|l|}{ Gender } \\
\hline Female & $7,788(46.5)$ & $1,031(38.7)$ & $944(44.4)$ \\
\hline Male & $8,976(53.5)$ & $1,635(61.3)$ & $1,182(55.6)$ \\
\hline \multicolumn{4}{|l|}{ Comorbidity } \\
\hline Ischemic heart disease except $\mathrm{MI}^{\mathrm{a}}$ & $1,863(11.1)$ & $513(19.2)$ & $244(11.5)$ \\
\hline Cerebrovascular disease except stroke ${ }^{b}$ & $537(3.2)$ & $124(4.7)$ & $86(4.0)$ \\
\hline Diabetes & $1,490(8.9)$ & $460(17.3)$ & $433(20.4)$ \\
\hline Chronic kidney disease & $1,063(6.3)$ & $502(18.8)$ & $338(15.9)$ \\
\hline Hypertension & $2,216(13.2)$ & $664(24.9)$ & $511(24.0)$ \\
\hline Peripheral vascular disease & $721(4.3)$ & $266(10.0)$ & $202(9.5)$ \\
\hline Cancer & $2,282(13.6)$ & $522(19.6)$ & $375(17.6)$ \\
\hline No surgery & $6,455(38.5)$ & $662(24.8)$ & $793(37.3)$ \\
\hline \multicolumn{4}{|l|}{ Surgery } \\
\hline Acute cardiac surgery & $195(1.2)$ & $88(3.3)$ & $59(2.8)$ \\
\hline Acute noncardiac surgery & $5,558(33.2)$ & $834(31.3)$ & $764(35.9)$ \\
\hline Elective cardiac surgery & $1,701(10.1)$ & $528(19.8)$ & $169(7.9)$ \\
\hline Elective noncardiac surgery & $2,855(17.0)$ & $554(20.8)$ & $341(16.0)$ \\
\hline \multicolumn{4}{|l|}{ Preadmission drug use } \\
\hline ACE inhibitors/AT2 antagonists & $2,677(16.0)$ & $763(28.6)$ & $698(32.8)$ \\
\hline Beta blockers & $2,318(13.8)$ & $667(25.0)$ & $487(22.9)$ \\
\hline Calcium channel antagonists & $1,587(9.5)$ & $483(18.1)$ & $401(18.9)$ \\
\hline Acetylsalicylic acid & $5,286(31.5)$ & $1,362(51.1)$ & $1,005(47.3)$ \\
\hline Diuretics & $1,348(8.0)$ & $357(13.4)$ & $272(12.8)$ \\
\hline Nitrates & $756(4.5)$ & $236(8.9)$ & $83(3.9)$ \\
\hline Statins & $2,533(15.1)$ & $671(25.2)$ & $441(20.7)$ \\
\hline NSAIDs & $2,486(14.8)$ & $430(16.1)$ & $436(20.5)$ \\
\hline \multicolumn{4}{|l|}{ Primary diagnosis during current hospitalization } \\
\hline Infectious diseases & $1,673(10.0)$ & $276(10.4)$ & $434(20.4)$ \\
\hline Endocrine diseases & $302(1.8)$ & $69(2.6)$ & $99(4.7)$ \\
\hline Cardiovascular diseases & $2,910(17.4)$ & $873(32.7)$ & $390(18.3)$ \\
\hline Respiratory diseases & $741(4.4)$ & $118(4.4)$ & $108(5.1)$ \\
\hline Gastrointestinal or liver diseases & $1,564(9.3)$ & $287(10.8)$ & $303(14.3)$ \\
\hline Cancer or other neoplasm & $2,463(14.7)$ & $471(17.7)$ & $304(14.3)$ \\
\hline Trauma or poisoning & $4,198(25.0)$ & $282(10.6)$ & $190(8.9)$ \\
\hline Other & $2,913(17.4)$ & $290(10.9)$ & $298(14.0)$ \\
\hline \multicolumn{4}{|l|}{ Laboratory information } \\
\hline Measured baseline creatinine & $10,213(60.9)$ & $2,143(80.4)$ & $1,610(75.7)$ \\
\hline Maximum creatinine during admission, ${ }^{\complement} \mu \mathrm{mol} / \mathrm{I}$, mean (IQR) & $74(62-88)$ & $123(101-149)$ & $254(180-397)$ \\
\hline \multicolumn{4}{|l|}{ ICU treatments } \\
\hline Mechanical ventilation & $4,362(26.0)$ & $1,297(48.6)$ & $1,126(53.0)$ \\
\hline
\end{tabular}


Table 2 Patient characteristics by AKI status among ICU patients surviving to hospital discharge, Northern Denmark, 2005 to 2010 (Continued)

Inotropes/vasopressors

$3,083(18.4)$

$1,158(43.4)$

$1,155(52.9)$

Length of admission

In-hospital days ${ }^{\mathrm{d}}$, median (IQR)

$8(3-15)$

15 (10-28)

$23(12-45)$

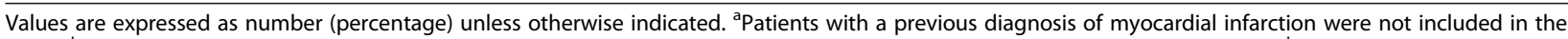
study; ${ }^{b}$ patients with a previous diagnosis of stroke were not included in the study; ${ }^{C}$ from ICU admission until hospital discharge; ${ }^{d}$ from hospital admission to hospital discharge. If date of discharge from one department and/or hospital and admission to another department and/or hospital was $\leq 1$ calendar day, this was considered as one hospital admission. ACE, angiotensin-converting enzyme; AKI, acute kidney injury; AT2, angiotensin 2; ICU, intensive care unit; IQR interquartile range; $n$, number; NSAIDS, nonsteroidal anti-inflammatory drugs.

the Danish Data Protection Agency (record number 2009-41-3987).

\section{Results}

\section{Characteristics of the study population}

The study population comprised 21,556 ICU patients who survived to hospital discharge, after excluding those with a previous kidney transplant or chronic dialysis treatment $(\mathrm{n}=314)$, those with a previous or concurrent diagnosis of $\mathrm{HF}, \mathrm{MI}$, or stroke $(\mathrm{n}=6,702)$, and those lacking a plasma creatinine measurement upon or after ICU admission $(\mathrm{n}=1,846)$. Compared to patients with a plasma creatinine measurement, patients lacking this measurement were younger, had less comorbidity, and had a markedly shorter hospital stay (Additional file 2). Median duration of follow-up was 2.7 years for all three study outcomes.

We found that $4,792(22.2 \%)$ of the 21,556 ICU patients had an episode of AKI; 2,666 (12.4\%) with AKI stage 1 and 2,126 (9.9\%) with AKI stages 2 to 3 . Patients with AKI were older, more often male, and had a higher degree of comorbidity than other ICU patients. AKI patients also were more frequently users of cardiovascular drugs and nonsteroidal anti-inflammatory drugs (NSAIDs) (Table 2). The primary diagnosis during the current hospitalization was most frequently trauma and poisoning for patients without AKI (25.0\%), cardiovascular disease for patients with AKI stage 1 (32.7\%), and infectious disease for patients with AKI stages 2 to 3 (20.4\%). Patients with AKI were more frequently treated with mechanical ventilation and inotropes/vasopressors and had longer hospital stays (Table 2). During follow-up, 2,569 (15.3\%) died without AKI, 619 (23.3\%) with AKI stage 1 and 558 (26.2\%) with AKI stages 2 to 3.

\section{Risk of heart failure}

During the three years following hospital discharge, 2.2\% of patients without AKI, $5.0 \%$ of patients with AKI stage 1, and $5.0 \%$ of patients with AKI stages 2 to 3 were hospitalized with first-time HF (Figure 1 and Table 3 ). Compared to patients without AKI, the adjusted HR was 1.33 (95\% CI, 1.06 to 1.66) for patients with AKI stage 1 and 1.45 (95\% CI, 1.14 to 1.84 ) for patients with AKI stages 2 to 3 (Table 3 ).

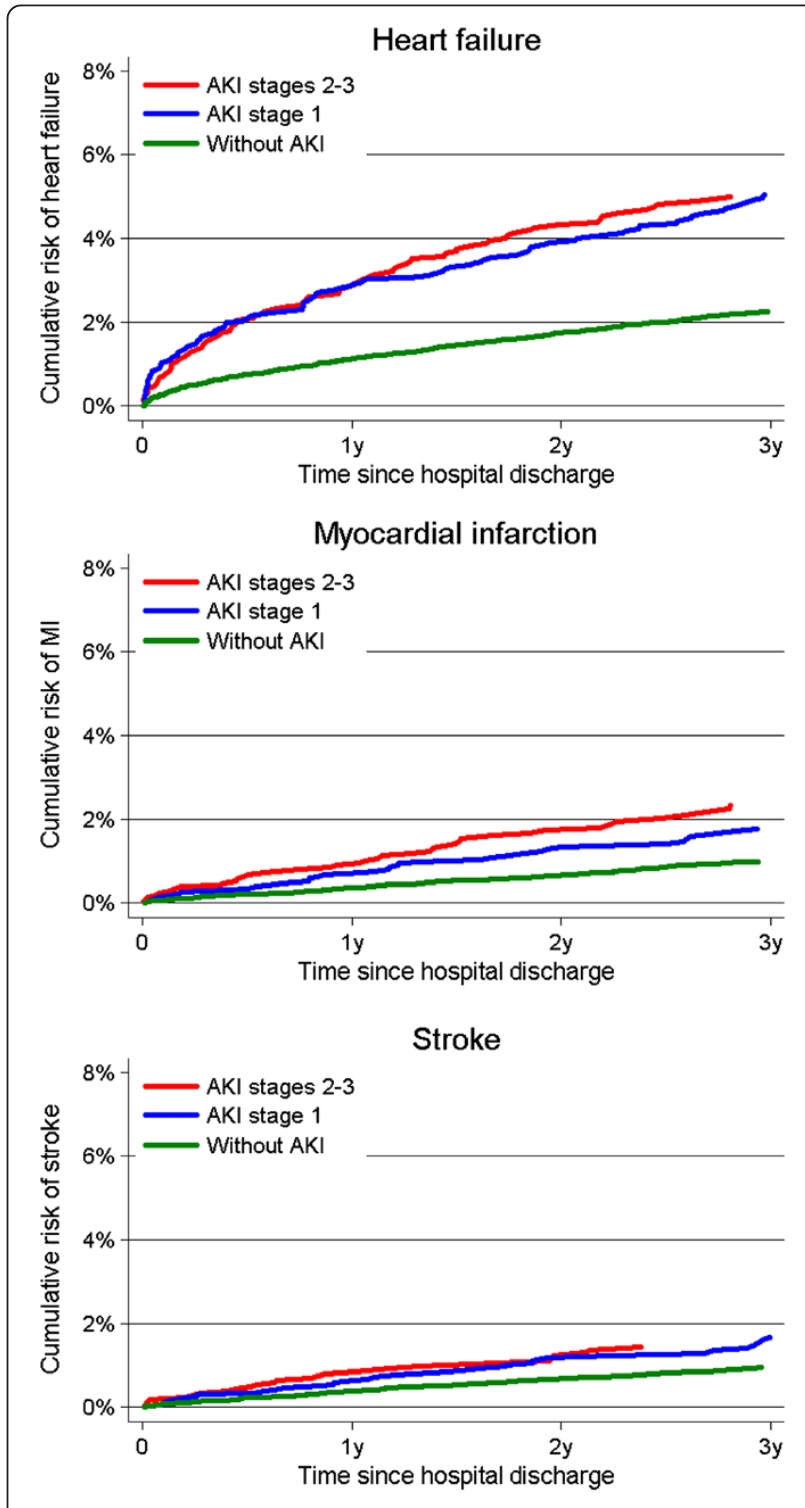

Figure 1 Three-year crude cumulative incidence of heart failure, myocardial infarction, and stroke by AKI stage. AKI, acute kidney injury. 
Table 3 Three-year risk of cardiovascular disease according to AKI stage, Northern Denmark, 2005 to 2010

\begin{tabular}{|c|c|c|c|c|c|c|c|c|c|c|}
\hline & \multicolumn{2}{|c|}{ Without AKI } & \multicolumn{4}{|c|}{ AKI stage 1} & \multicolumn{4}{|c|}{ AKI stages 2-3 } \\
\hline & Events, $n$ & $\begin{array}{l}\text { Cumulative risk } \\
\%(95 \% \mathrm{Cl})\end{array}$ & Events, $n$ & $\begin{array}{l}\text { Cumulative risk } \\
\%(95 \% \mathrm{Cl})\end{array}$ & $\begin{array}{l}\text { Unadjusted HR } \\
(95 \% \mathrm{Cl})\end{array}$ & $\begin{array}{l}\text { Adjusted } \mathrm{HR}^{\mathrm{a}} \\
(95 \% \mathrm{Cl})\end{array}$ & Events, $n$ & $\begin{array}{l}\text { Cumulative risk } \\
\%(95 \% \mathrm{CI})\end{array}$ & $\begin{array}{l}\text { Unadjusted HR } \\
(95 \% \mathrm{Cl})\end{array}$ & $\begin{array}{l}\text { Adjusted } \mathrm{HR}^{\mathrm{a}} \\
(95 \% \mathrm{Cl})\end{array}$ \\
\hline$\overline{\mathrm{HF}}$ & 320 & $2.2(2.0-2.5)$ & 114 & $5.0(4.2-6.0)$ & $2.43(1.96-3.01)$ & $1.33(1.06-1.66)$ & 91 & $5.0(4.0-6.1$ & $2.53(2.01-3.01)$ & $1.45(1.14-1.84)$ \\
\hline Ml & 135 & $1.0(0.8-1.2)$ & 38 & $1.8(1.3-2.4)$ & $1.93(1.35-2.76)$ & $1.04(0.71-1.51)$ & 40 & $2.3(1.7-3.1)$ & $2.68(1.88-3.82)$ & $1.51(1.05-2.18)$ \\
\hline Stroke & 131 & $0.9(0.8-1.1)$ & 35 & $1.7(1.2-2.4)$ & $1.83(1.26-2.65)$ & $1.10(0.75-1.62)$ & 26 & $1.4(1.0-2.1)$ & 1.79 (1.17-2.72) & $1.07(0.70-1.65)$ \\
\hline
\end{tabular}
current hospitalization, and preadmission use of drugs listed in Table 2. AKI, acute kidney injury; Cl, confidence interval; $\mathrm{HF}$, heart failure; $\mathrm{HR}$, hazard ratio; ICU, intensive care unit; $\mathrm{MI}, \mathrm{myoc}$ ordial infarction; $\mathrm{n}$, number. 


\section{Risk of myocardial infarction}

The three-year cumulative risk of MI was 1.0\% for patients without AKI, $1.8 \%$ for patients with AKI stage 1 and 2.3\% for patients with AKI stages 2 to 3 (Figure 1 and Table 3). The adjusted HR was 1.04 (95\% CI, 0.71 to 1.51 ) for patients with AKI stage 1 and 1.51 (95\% CI, 1.05 to 2.18) for patients with AKI stages 2 to 3 (Table 3 ).

\section{Risk of stroke}

Stroke risk within the first three years after hospital discharge was $0.9 \%$ for patients without AKI, $1.7 \%$ for patients with AKI stage 1, and $1.4 \%$ for patients with AKI stages 2 to 3 (Figure 1 and Table 3). The adjusted HRs were 1.10 (95\% CI, 0.75 to 1.62 ) for patients with AKI stage 1 and 1.07 (95\% CI, 0.70 to 1.65 ) for patients with AKI stages 2 to 3 (Table 3).

\section{Renal recovery}

Of the 4,792 ICU patients with AKI who survived to hospital discharge, 3,888 (81.1\%) recovered renal function by the time of discharge. The increased risk of HF following any stage of AKI and of MI following AKI stages 2 to 3 persisted in patients who recovered their renal function, although their risk was lower than among patients without renal recovery (Table 4).

\section{Sensitivity analysis}

The associations between AKI and heart failure, MI and stroke were similar after imputation of AKI level in patients without a measured plasma creatinine upon or after ICU admission. Please see Additional file 3.

\section{Discussion}

In this population-based study of more than 21,000 ICU survivors, patients with AKI stages 2 to 3 were at 50\% increased risk of $\mathrm{HF}$ and $\mathrm{MI}$ in the three-year follow-up period. Even AKI stage 1 was associated with increased risk of HF. The increased risk persisted in patients who recovered their renal function by the time of hospital discharge, but was less pronounced than the risk among patients without recovery of renal function. No associations were found between AKI and stroke or between AKI stage 1 and MI.

\section{Other studies}

Our study is the first to examine the impact of AKI on first-time hospitalization for HF, MI, and stroke following an ICU stay. Previous studies primarily examined the impact on subsequent cardiovascular disease of AKI secondary to HF, MI or coronary intervention [13-18], and none focused on first-time cardiovascular events [13-19].

Five earlier studies examined the impact of AKI on HF [13-16,19]. Similar to our findings among ICU patients with AKI, they reported that AKI, as a complication of coronary angiography [13], MI [14], coronary arterial bypass grafting (CABG) surgery [15], HF [16], and HIV [19] increased the risk of hospitalization for subsequent HF. In a Canadian cohort of 14,782 patients who underwent coronary angiography, procedures complicated by AKI were associated with increased risk of subsequent hospital admission for HF after median follow-up of 20 months. The adjusted HRs ranged from 1.48 (95\% CI, 1.16 to 1.91 ) for patients with AKI stage 1 to 2.17 (95\% CI, 1.49 to 3.15) for patients with AKI stages 2 to 3 [13]. Similarly, a single-center Israeli study of 1,957 patients admitted for ST-elevation MI found that during median follow-up of 36 months AKI was associated with subsequent risk of HF among patients who survived until hospital discharge. This study also found that the association persisted in patients who recovered renal function before hospital discharge, which our findings confirmed [14]. A large Swedish study of 24,018 patients who underwent CABG surgery found that among 30-day survivors the adjusted HR of HF during mean follow-up of 4.1 years was 1.69 (95\% CI, 1.48 to 1.94 ), 2.33 (95\% CI, 1.69 to 3.22) and 1.87 (95\% CI, 0.84 to 4.20 ) for AKI stages 1, 2 and 3, respectively [15]. The association between AKI and subsequent increased risk of HF was also evident in a cohort of US veterans with HIV who survived the first three months after hospital discharge. Choi et al. reported an adjusted HR of subsequent HF of 1.17 (95\% CI, 1.34 to 2.35) in patients with stage $1 \mathrm{AKI}, 2.11$ (95\% CI, 1.07 to 2.35 ) in patients with AKI stages 2 to 3 not requiring dialysis, and 4.20 (95\% CI, 2.24 to 7.88$)$ in patients with AKI stages 2 to 3 requiring dialysis, during mean follow-up of 5.7 years [19]. In addition, a Chinese single-center study

Table 4 Three-year risk of cardiovascular disease stratified by renal recovery status at hospital discharge ${ }^{a}$

\begin{tabular}{|c|c|c|c|c|}
\hline & \multicolumn{2}{|c|}{ Recovery $(n=3,888)$} & \multicolumn{2}{|c|}{ Nonrecovery $(n=904)$} \\
\hline & $\begin{array}{l}\text { Events } \\
\mathrm{n}\end{array}$ & $\begin{array}{l}\text { Adjusted HR } \\
(95 \% \mathrm{Cl})\end{array}$ & $\begin{array}{l}\text { Events } \\
\mathrm{n}\end{array}$ & $\begin{array}{l}\text { Adjusted } \mathrm{HR}^{\mathrm{b}} \\
(95 \% \mathrm{Cl})\end{array}$ \\
\hline \multicolumn{5}{|l|}{ AKI stage 1} \\
\hline Heart failure & 98 & $1.26(1.00-1.60)$ & 15 & $1.81(1.07-3.07)$ \\
\hline $\begin{array}{l}\text { Myocardial } \\
\text { infarction }\end{array}$ & 35 & $1.05(0.72-1.55)$ & 3 & $0.79(0.25-2.51)$ \\
\hline Stroke & 32 & $1.142(0.77-1.70)$ & 3 & $0.98(0.31-3.10)$ \\
\hline \multicolumn{5}{|c|}{ AKI stages $2-3$} \\
\hline Heart failure & 62 & $1.50(1.13-1.98)$ & 30 & $1.42(0.96-2.10)$ \\
\hline $\begin{array}{l}\text { Myocardial } \\
\text { infarction }\end{array}$ & 23 & $1.31(0.83-2.07)$ & 17 & $1.97(1.17-3.32)$ \\
\hline Stroke & 19 & $1.16(0.71-1.90)$ & 7 & $0.94(0.43-2.04)$ \\
\hline
\end{tabular}

${ }^{a}$ Compared to ICU patients without AKI; ${ }^{b}$ adjusted for age, gender, other ischemic heart diseases, other cerebrovascular diseases, hypertension, peripheral vascular disease, diabetes, chronic kidney disease, cancer, surgical status, primary diagnosis during current hospitalization, and preadmission use of drugs listed in Table 2.

AKI, acute kidney injury; $\mathrm{Cl}$, confidence interval; $\mathrm{HR}$, hazard ratio; $\mathrm{ICU}$, intensive care unit; $n$, number. 
of 1,005 patients found that patients hospitalized for HF complicated by AKI were readmitted more frequently for HF during the following year [16].

A few studies have examined risk of MI after AKI in different study populations $[13,14,17,18]$. Like our ICU study, they found that AKI was associated with later MI. However, these relatively small studies were hampered by imprecise risk estimates $[13,14]$. The study by James et al. found that the adjusted HRs of MI complicated by AKI stage 1 and AKI stages 2 to 3 were 1.47 (95\% CI, 1.12 to 1.91 ) and 1.19 (95\% CI, 0.70 to 2.02), respectively, compared with non-AKI patients. The Israeli study by Goldberg et al. found that the adjusted HR of recurrent MI after initial MI complicated by AKI was 1.6 (95\% CI, 0.9 to 1.8) for patients with mild AKI who did not regain renal function by hospital discharge, 1.4 (95\% CI, 0.7 to 3.0) for patients with moderate/severe AKI who did regain renal function, and 1.4 (95\% CI, 0.7 to 2.8) for those with moderate/severe AKI who did not recover renal function. However, they found no increased risk of MI among patients with mild AKI who regained renal function (adjusted $\mathrm{HR}=0.6$ (95\% CI, 0.2 to 1.8). In their single-center study, Lindsay et al. found that AKI (serum creatinine $>50 \%$ over baseline) after percutaneous intervention was associated with a twofold increased risk of MI among hospital survivors (adjusted OR $=2.0 ; 95 \% \mathrm{CI}, 1.3$ to 3.2). A Danish singlecenter study among elective cardiac surgical patients found a nonsignificant association between AKI and increased MI risk (five-year adjusted $\mathrm{HR}=1.5$ (95\% CI, 0.7 to 3.2)) [18].

To our knowledge, only two studies have examined the association between AKI and long-term (beyond 90 days) risk of stroke $[13,18]$. In line with our results, these studies did not find marked evidence for an association between AKI and subsequent hospitalization with stroke $[13,18]$.

\section{Strengths and limitations}

The main strengths of this study are its populationbased design in the setting of a uniform tax-supported health care system providing equal access to health care. As well, patient follow-up was virtually complete, and data on ICU admissions were highly valid. This reduced potential selection bias.

Several limitations should be considered when interpreting our results. First, like most other studies of AKI, we lacked data on urine output and thus could not include the urine output criteria specified in the KDIGO classification. Therefore, we may have underestimated the prevalence of AKI compared to the use of both plasma creatinine and urine output criteria [40]. Second, we excluded patients without measured plasma creatinine upon or after ICU admission, which potentially could introduce selection bias. However, our results were similar after imputation of AKI level for patients without a plasma creatinine measurement. Third, despite the fact that we had access to all plasma creatinine measurements for outpatient clinic or general practitioner visits in the study area, we did not have a measured baseline creatinine for $35 \%$ of the ICU patients. We therefore estimated baseline creatinine as previously suggested [27]. This may, however, underestimate the AKI prevalence in patients without CKD [41]. In addition, even a measured plasma creatinine measurement from an outpatient clinic or a general practitioner visit, which was available in $65 \%$ of the included patients, may not truly reflect a baseline creatinine level. Fourth, our outcome assessment relies on correct coding. Previous studies have found that the positive predictive values of discharge diagnoses recorded for HF, MI, and stroke are 81\% [42], 92\% [43], and 84\% [44], respectively. However, any misclassification is expected to be nondifferential, biasing the study toward a null result. Fifth, we had few outcomes for MI and stroke, resulting in imprecise estimates. Six, patients with coexisting HF may have been undiagnosed due to this disease's asymptomatic nature in its early phase. The association between AKI and apparent subsequent HF therefore could be partly due to reverse causation. Finally, although we controlled for potential confounders using highly valid data on known comorbidities and drug use, our results may have been affected by unmeasured or residual confounding, such as undiagnosed cardiac dysfunction and severity of various comorbidities.

\section{Conclusions}

AKI stages 2 to 3 in surviving ICU patients is associated with increased risk of HF and MI up to three years after hospital discharge. The association of HF was evident even among patients with AKI stage 1. These associations were less pronounced but persisted among patients who had recovered renal function by hospital discharge. This may suggest a need for systematic follow-up of patients discharged after an AKI episode, especially those who do not regain their renal function before discharge.

\section{Key messages}

- Acute kidney injury is associated with increased risk of heart failure and myocardial infarction, but not stroke.

- The increased risk of heart failure and myocardial infarction persisted among patients who had recovered renal function by hospital discharge.

\section{Additional files}

Additional file 1: Relevant codes used in the current study. Additional file 2: Characteristics of patients with missing plasma creatinine measurements, patients without AKI, and with AKI. 
Additional file 3: Adjusted HR of cardiovascular diseases after multiple imputation of AKI stages in patients without measured plasma creatinine from ICU admission to hospital discharge.

\section{Abbreviations}

AKl: acute kidney injury; ATC: anatomic therapeutic chemical classification system; CABG: coronary arterial bypass grafting; Cl: confidence interval; CKD: chronic kidney disease; DNRP: Danish National Registry of Patients; eGFR: estimated glomerular filtration rate; HF: heart failure; HIV: human immunodeficiency virus; HR: hazard ratio; ICD-10: International Classification of Disease, $10^{\text {th }}$ revision; ICU: intensive care unit; IQR: interquartile range; KDIGO: Kidney Disease Improving Global Outcome; MDRD: Modification of Diet in Renal Disease; MI: myocardial infarction; NSAIDS: nonsteroidal anti-inflammatory drugs.

\section{Competing interests}

The authors declare that they have no competing interests.

\section{Authors' contributions}

HG participated in the conception and design of the study, did the statistical analyses, reviewed the literature, analyzed and interpreted the data, and drafted the manuscript. CFC participated in the conception and design of the study, analyzed and interpreted the data, and revised the manuscript critically for important intellectual content. MBJ participated in the conception and design of the study, acquisition of data, analyzed and interpreted the data, and revised the manuscript critically for important intellectual content. ET analyzed and interpreted the data, and revised the manuscript critically for important intellectual content. BJ analyzed and interpreted the data and revised the manuscript critically for important intellectual content. HTS participated in design of the study, acquisition of data, analyzed and interpreted the data, and revised the manuscript critically for important intellectual content. All authors read and approved the final version.

\section{Acknowledgments}

The study was made possible through financial support from the Danish Medical Research Council (record number 271-05-0511), the Clinical Epidemiology Research Foundation, and a grant from Aarhus University Research Foundation. The design, collection, analysis and interpretation of data, plus writing and publication of the manuscript were done by the authors without participation or influence from any of the funding sources.

\section{Author details}

'Department of Clinical Epidemiology, Aarhus University Hospital, Olof Palmes Allé 43-45, Aarhus DK-8200, Denmark. ²Departments of Anesthesiology and Intensive Care Medicine, Aarhus University Hospital, Brendstrupgårdsvej 100, Aarhus DK-8200, Denmark. ${ }^{3}$ Department of Renal Medicine, Aarhus University Hospital, Skejley Sygehus, Aarhus DK-8200, Denmark.

Received: 22 April 2014 Accepted: 5 August 2014

Published online: 14 October 2014

\section{References}

1. Bagshaw SM, George C, Dinu I, Bellomo R: A multi-centre evaluation of the RIFLE criteria for early acute kidney injury in critically ill patients. Nephrol Dial Transplant 2008, 23:1203-1210.

2. Ostermann M, Chang RW: Acute kidney injury in the intensive care unit according to RIFLE. Crit Care Med 2007, 35:1837-1843.

3. Mandelbaum T, Scott DJ, Lee J, Mark RG, Malhotra A, Waikar SS, Howell MD, Talmor D: Outcome of critically ill patients with acute kidney injury using the Acute Kidney Injury Network criteria. Crit Care Med 2011, 39:2659-2664.

4. Hoste EA, Clermont G, Kersten A, Venkataraman R, Angus DC, De BD, Kellum JA: RIFLE criteria for acute kidney injury are associated with hospital mortality in critically ill patients: a cohort analysis. Crit Care 2006, 10:R73.

5. Thakar CV, Christianson A, Freyberg R, Almenoff P, Render ML: Incidence and outcomes of acute kidney injury in intensive care units: a Veterans Administration study. Crit Care Med 2009, 37:2552-2558.
6. Gammelager $\mathrm{H}$, Christiansen $\mathrm{CF}$, Johansen MB, Tonnesen $\mathrm{E}$, Jespersen $\mathrm{B}$, Sorensen HT: One-year mortality among Danish intensive care patients with acute kidney injury: a cohort study. Crit Care 2012, 16:R124.

7. Lo LJ, Go AS, Chertow GM, McCulloch CE, Fan D, Ordonez JD, Hsu CY: Dialysis-requiring acute renal failure increases the risk of progressive chronic kidney disease. Kidney Int 2009, 76:893-899.

8. Wald R, Quinn RR, Luo J, Li P, Scales DC, Mamdani MM, Ray JG: Chronic dialysis and death among survivors of acute kidney injury requiring dialysis. JAMA 2009, 302:1179-1185

9. Chuasuwan A, Kellum JA: Cardio-renal syndrome type 3: epidemiology, pathophysiology, and treatment. Semin Nephrol 2012, 32:31-39.

10. Go AS, Chertow GM, Fan D, McCulloch CE, Hsu CY: Chronic kidney disease and the risks of death, cardiovascular events, and hospitalization. $N$ Engl J Med 2004, 351:1296-1305.

11. Kelly KJ: Distant effects of experimental renal ischemia/reperfusion injury. J Am Soc Nephrol 2003, 14:1549-1558.

12. Burchill L, Velkoska E, Dean RG, Lew RA, Smith Al, Levidiotis V, Burrell LM: Acute kidney injury in the rat causes cardiac remodelling and increases angiotensin-converting enzyme 2 expression. Exp Physiol 2008, 93:622-630.

13. James MT, Ghali WA, Knudtson ML, Ravani P, Tonelli M, Faris P, Pannu N, Manns BJ, Klarenbach SW, Hemmelgarn BR, Alberta Provincial Project for Outcome Assessment in Coronary Heart Disease (APPROACH) Investigators: Associations between acute kidney injury and cardiovascular and renal outcomes after coronary angiography. Circulation 2011, 123:409-416.

14. Goldberg A, Kogan E, Hammerman H, Markiewicz W, Aronson D: The impact of transient and persistent acute kidney injury on long-term outcomes after acute myocardial infarction. Kidney Int 2009, 76:900-906.

15. Olsson D, Sartipy U, Braunschweig F, Holzmann MJ: Acute kidney injury following coronary artery bypass surgery and long-term risk of heart failure. Circ Heart Fail 2013, 6:83-90.

16. Zhou Q, Zhao C, Xie D, Xu D, Bin J, Chen P, Liang M, Zhang X, Hou F: Acute and acute-on-chronic kidney injury of patients with decompensated heart failure: impact on outcomes. BMC Nephrol 2012, 13:51.

17. Lindsay J, Apple S, Pinnow EE, Gevorkian N, Gruberg L, Satler LF, Pichard $A D$, Kent KM, Suddath W, Waksman R: Percutaneous coronary intervention-associated nephropathy foreshadows increased risk of late adverse events in patients with normal baseline serum creatinine. Catheter Cardiovasc Interv 2003, 59:338-343.

18. Hansen MK, Gammelager H, Mikkelsen MM, Hjortdal VE, Layton JB, Johnsen SP, Christiansen CF: Post-operative acute kidney injury and five-year risk of death, myocardial infarction, and stroke among elective cardiac surgical patients: a cohort study. Crit Care 2013, 17:R292.

19. Choi Al, Li Y, Parikh C, Volberding PA, Shlipak MG: Long-term clinical consequences of acute kidney injury in the HIV-infected. Kidney Int 2010, 78:478-485.

20. McCullough PA, Ahmad A: Cardiorenal syndromes. World J Cardiol 2011, 3:1-9.

21. Frank L: Epidemiology. When an entire country is a cohort. Science 2000, 287:2398-2399.

22. Lynge E, Sandegaard JL, Rebolj M: The Danish National Patient Register. Scand J Public Health 2011, 39:30-33.

23. Grann AF, Erichsen R, Nielsen AG, Froslev T, Thomsen RW: Existing data sources for clinical epidemiology: the clinical laboratory information system (LABKA) research database at Aarhus University, Denmark. Clin Epidemiol 2011, 3:133-138.

24. Disease K, Improving Global Outcomes (KDIGO) Acute Kidney Injury Work Group: KDIGO clinical practice guideline for acute kidney injury. Kidney Int Supp/ 2012, 2:1-138.

25. Miles RR, Roberts RF, Putnam AR, Roberts WL: Comparison of serum and heparinized plasma samples for measurement of chemistry analytes. Clin Chem 2004, 50:1704-1706.

26. Go AS, Parikh CR, Ikizler TA, Coca S, Siew ED, Chinchilli VM, Hsu CY, Garg AX, Zappitelli M, Liu KD, Reeves WB, Ghahramani N, Devarajan P, Faulkner GB, Tan TC, Kimmel PL, Eggers P, Stokes JB, Assessment Serial Evaluation, and Subsequent Sequelae of Acute Kidney Injury Study Investigators: The assessment, serial evaluation, and subsequent sequelae of acute kidney injury (ASSESS-AKI) study: design and methods. BMC Nephrol 2010, 11:22.

27. Bellomo R, Ronco C, Kellum JA, Mehta RL, Palevsky P: Acute renal failure definition, outcome measures, animal models, fluid therapy and information technology needs: the Second International Consensus Conference of the Acute Dialysis Quality Initiative (ADQI) Group. Crit Care 2004, 8:R204-R212. 
28. Bihorac A, Yavas S, Subbiah S, Hobson CE, Schold JD, Gabrielli A, Layon AJ, Segal MS: Long-term risk of mortality and acute kidney injury during hospitalization after major surgery. Ann Surg 2009, 249:851-858.

29. Ehrenstein V, Antonsen S, Pedersen L: Existing data sources for clinical epidemiology: Aarhus University Prescription Database. Clin Epidemiol 2010, 2:273-279

30. American Diabetes Association: Diagnosis and classification of diabetes mellitus. Diabetes Care 2013, 36:567-S74.

31. Johannesdottir SA, Schmidt M, Phillips G, Glaser R, Yang EV, Blumenfeld M, Lemeshow S: Use of beta-blockers and mortality following ovarian cancer diagnosis: a population-based cohort study. BMC Cancer 2013, 13:85.

32. Coviello V, Boggess M: Cumulative incidence estimation in the presence of competing risks. Stata J 2004, 4:103-112.

33. Andersen PK, Geskus RB, de Witte T, Putter H: Competing risks in epidemiology: possibilities and pitfalls. Int J Epidemiol 2012, 41:861-870.

34. Royston P: Multiple imputation of missing values. Stata J 2004, 4:227-241.

35. Royston P: Multiple imputation of missing values: Update of ice. Stata J 2005, 5:527-536.

36. Royston P: Multiple imputation of missing values: update. Stata J 2005 5:188-201.

37. White IR, Royston P: Imputing missing covariate values for the Cox model. Stat Med 2009, 28:1982-1998.

38. Act on research ethics treatment of health research. (Law No. 593 of 14 June 2011): Chapter 4, \$14, stk. 2 [https://www.retsinformation.dk/Forms/ R0710.aspx?id=137674] [In Danish].

39. Getting started with clinical research - instructions about preparation and approval of clinical research. Danish Ministry of Health. http://www.sum.dk/ /media/Filer\%20-\%20Publikationer_i_pdf/2011//kinisk\%20forskning/ Klinisk-forskning-pub.ashx [In Danish].

40. Wlodzimirow KA, Abu-Hanna A, Slabbekoorn M, Chamuleau RA, Schultz MJ Bouman CS: A comparison of RIFLE with and without urine output criteria for acute kidney injury in critically ill patients. Crit Care 2012, 16:R200.

41. Bagshaw SM, Uchino S, Cruz D, Bellomo R, Morimatsu H, Morgera S, Schetz M, Tan I, Bouman C, Macedo E, Gibney N, Tolwani A, Oudemans-van S, Ronco C, Kellum JA: A comparison of observed versus estimated baseline creatinine for determination of RIFLE class in patients with acute kidney injury. Nephrol Dial Transplant 2009, 24:2739-2744.

42. Kumler T, Gislason GH, Kirk V, Bay M, Nielsen OW, Kober L, Torp-Pedersen C: Accuracy of a heart failure diagnosis in administrative registers. Eur $J$ Heart Fail 2008, 10:658-660.

43. Joensen AM, Jensen MK, Overvad K, Dethlefsen C, Schmidt E, Rasmussen L, Tjonneland A, Johnsen S: Predictive values of acute coronary syndrome discharge diagnoses differed in the Danish National Patient Registry. J Clin Epidemiol 2009, 62:188-194.

44. Krarup LH, Boysen $\mathrm{G}$, Janjua H, Prescott E, Truelsen $\mathrm{T}$ : Validity of stroke diagnoses in a National Register of Patients. Neuroepidemiology 2007, 28:150-154.

doi:10.1186/s13054-014-0492-2

Cite this article as: Gammelager et al:: Three-year risk of cardiovascular disease among intensive care patients with acute kidney injury: a population-based cohort study. Critical Care 2014 18:492.

\section{Submit your next manuscript to BioMed Central and take full advantage of:}

- Convenient online submission

- Thorough peer review

- No space constraints or color figure charges

- Immediate publication on acceptance

- Inclusion in PubMed, CAS, Scopus and Google Scholar

- Research which is freely available for redistribution

Submit your manuscript at www.biomedcentral.com/submit 